\title{
CAEP Annual Scientific Assembly
}

\author{
Saint John, New Brunswick, June 10-14, 2000
}

\section{FORMS OF SUBMISSION}

Abstracts related to the objectives and topics of the Canadian Association of Emergency Physicians and Emergency Medicine, will be considered in two forms:

- 10-minute oral presentation (additional 5-minute discussion for questions);

- Poster Session.

\section{INSTRUCTIONS FOR PREPARING ABSTRACTS}

- Please follow instructions closely. Failure to do so will result in abstract disqualification.

- The abstract must be typed single-space, clear and legible. Photocopies of abstract form are acceptable but typed abstracts must be original. Abstracts may be submitted in English or French.

- The entire abstract, including title, author(s), institutional affiliation of first author, and text must fit within the box provided. Please do not use photo reduction.

- Publication of the original abstract in CJEM will be completed once versions of the accepted abstracts are received from the author via email.

- The abstract must contain, in the following order:

- All fonts should be ARIAL.

- Title of paper: use 12-point boldface type; capitalize each word; do not use abbreviations in the title; follow title with a carriage return.

- Last name and initials of authors without degrees or titles (12-point). Underline the name of the author who will present the paper. Primary author listed first.

- Institutional affiliation, city, province of primary author only.

- Skip a line after the affiliation. For remainder of the abstract, excluding the title, the height of the letters must be 10point font; type density must be no more than 15 characters per inch.

- Text of abstract: Left-sided justification only; keep abbreviations to a minimum (and define when first used). Graphs and tables must fit within abstract box. Where appropriate, the text should be structured using the following headings: a) Objectives b) Methods c) Results d) Conclusions. Each heading should be underlined. Maximum length: 300 words.

\section{INSTRUCTIONS FOR PREPARING SUBMISSION}

- All abstracts must be sent by courier (unfolded and unstapled) or via email for receipt on or before March 1, 2000 to: CAEP, Suite 104, 1785 Alta Vista Dr., Ottawa ON K1G 3 Y6.

- Notification of acceptance will be transmitted via email or fax no later than March 30th.

- A copy of all accepted abstracts will need to be emailed to CAEP before the meeting; an email contact is mandatory.

Example:

THE DOSE OF ORAL, INHALED AND PARENTERAL CORTICOSTEROIDS IN ACUTE SEVERE AIRWAY DISEASES TREATED IN THE ED.

Bloggs JA, Smith LT, Murray M. University of Alberta, Edmonton, AB.

Objectives: To compare the Emergency Department (ED) use of inhaled (ICS), oral (CS), intravenous (IV) and intramuscular (IM) corticosteroids for patients with acute bronchial asthma and chronic obstructive pulmonary disease (COPD). 


\section{CAEP Annual Scientific Assembly}

Saint John, NB, June 10-14, 2000

Please type name and mailing address of First Author.

First name

Surname

Title/Affiliation

\section{Department}

\section{Address}

City

Telephone Number

Province
Fax Number

Fax Number

$\square$ Oral Presentation
Postal Code

E-mail Address (imperative)

Please consider my abstract for:

$\square$ Poster Presentation

Presentation

\section{ABSTRACT}

Primarily research conducted by a student/resident (must be first author and presenter): $\square$ Yes $\square$ No

First Author's Signature

$\frac{1}{\text { day }} / 2000$

Mail by courier for receipt on or before March 1, 2000 to: CAEP, Suite 104, 1785 Alta Vista Dr., Ottawa, ON K1G 3 Y6 or electronically to CAEP; abstracts@ caep.ca 